\title{
Tumor necrosis factor-a blockade in recurrent and disabling chronic sciatica associated with post-operative peridural lumbar fibrosis: results of a double-blind, placebo randomized controlled study
}

Christelle Nguyen ${ }^{1,2^{*}}$, Clémence Palazzo ${ }^{1,3}$, Sophie Grabar ${ }^{4,5}$, Antoine Feydy ${ }^{6}$, Katherine Sanchez ${ }^{1}$, Nathalie Zee ${ }^{6}$, Laurent Quinquis ${ }^{4}$, Myriam Ben Boutieb ${ }^{4}$, Michel Revel ${ }^{1}$, Marie-Martine Lefèvre-Colau', Serge Poiraudeau ${ }^{1,3}$ and François Rannou, ${ }^{1,2}$

\begin{abstract}
Introduction: The aim of this study was to assess the efficacy and safety of tumor necrosis factor (TNF)-a inhibition with infliximab (IFX) in treating recurrent and disabling chronic sciatica pain associated with post-operative peridural lumbar fibrosis.
\end{abstract}

Method: A double-blind, placebo-controlled study randomized 35 patients presenting with sciatica pain associated with post-operative peridural lumbar fibrosis to two groups: IFX $(n=18)$, a single intravenous injection of $3 \mathrm{mg} / \mathrm{kg}$ IFX; and placebo $(n=17)$, a single saline serum injection. The primary outcome was a $50 \%$ reduction in sciatica pain on a visual analog scale (VAS) at day 10. Secondary outcomes were radicular and lumbar VAS pain at day 0 and radicular and lumbar VAS pain, Québec disability score, drug-sparing effect and tolerance at days 10, 30, 90, and 180.

Results: At day 10, the placebo and IFX groups did not differ in the primary outcome (50\% reduction in sciatica pain observed in three $(17.6 \%)$ versus five $(27.8 \%)$ patients; $p=0.69)$. The number of patients reaching the patient acceptable symptom state for radicular pain was significantly higher in the placebo than IFX group after injection (12 (70.6 \%) versus five $(27.8 \%)$ patients; $p=0.01)$. The two groups were comparable for all other secondary outcomes.

Conclusion: Treatment with a single $3 \mathrm{mg} / \mathrm{kg}$ IFX injection for post-operative peridural lumbar fibrosis-associated sciatica pain does not significantly reduce radicular symptoms at day 10 after injection.

Trial registration: ClinicalTrials.gov NCT00385086; registered 4 October 2006 (last updated 15 October 2015). Keywords: TNF-a blockade, Infliximab, Sciatica, Post-operative lumbar peridural fibrosis, Randomized controlled trial

\footnotetext{
* Correspondence: christelle.nguyen2@aphp.fr

'Univ. Paris Descartes, PRES Sorbonne Paris Cité, Service de Rééducation et

Réadaptation de l'Appareil Locomoteur et des Pathologies du Rachis, Hôpital

Cochin, Assistance Publique - Hôpitaux de Paris, Paris, France

${ }^{2}$ Univ. Paris Descartes, PRES Sorbonne Paris, Cité Laboratoire de

Pharmacologie, Toxicologie et Signalisation Cellulaire, INSERM UMR-S 1124,

UFR Biomédicale des Saints Pères, Paris, France

Full list of author information is available at the end of the article
}

\section{Biomed Central}

(c) 2015 Nguyen et al. Open Access This article is distributed under the terms of the Creative Commons Attribution 4.0 International License (http://creativecommons.org/licenses/by/4.0/), which permits unrestricted use, distribution, and reproduction in any medium, provided you give appropriate credit to the original author(s) and the source, provide a link to the Creative Commons license, and indicate if changes were made. The Creative Commons Public Domain Dedication waiver (http://creativecommons.org/publicdomain/zero/1.0/) applies to the data made available in this article, unless otherwise stated. 


\section{Introduction}

The prevalence of persistent or recurrent post-operative back or lower limb pain in patients who undergo discectomy or laminectomy is up to $15 \%$ [1], and management remains challenging. Recurrent symptoms in the legs are thought to be related to recurrent disc herniation, persistent herniated fragment, spinal stenosis, or post-operative peridural fibrosis secondary to scar formation [2,3]. Extended peridural fibrosis is associated with poor surgical outcomes in $24 \%$ of patients after disc herniation surgery [3]. Peridural scarring is consistently observed after spinal surgery including discectomy $[4,5]$ or laminectomy $[6,7]$. However, with extended and adhesive post-operative peridural fibrosis being associated with inflammatory changes at the surgical site, nerve root and dural sac neuromechanics are impaired, which ultimately leads to nerve root compression, abnormal dura and nerve root bounding and traction during back and limb movements $[1,8]$. Peridural fibrosis may also impair the diffusion of nutrients causing nerve root starvation [9]. Patients with post-operative peridural lumbar fibrosis-associated sciatica pain often experience loss of function, disability and impaired quality of life and can require the use of opioid analgesics [10]. Etiologic diagnosis of recurrent or persistent post-operative sciatica is currently based on magnetic resonance imaging (MRI), which helps distinguish central and lateral spinal stenosis from disc herniation, persistent herniated fragment or peridural fibrosis [11]. In the case of peridural fibrosis, MRI demonstrates hyposignals in T1weighted sequences with enhancement after gadolinium injection and hypersignals in T2-weighted sequences of the fibrotic tissue in the peridural space.

Key and Ford first demonstrated that experimental destruction of the intervertebral disc peripheral annulus fibrosus resulted in peridural scarring [4]. Three factors causing scar formation were peridural fat destruction, peridural hematoma and invasion of the surgical trajectory by paravertebral muscle fibers [7]. Treatments targeting one of these three factors included: interposition of biological material such as fat and animal collagen fibers [12-16]; nonbiological material such as absorbing gelatin sponge, silastic membrane, wax for bone hemostasis or polyglactine 910 [7, 13, 15, 17-19]; and viscous material such as carboxymethylcellulosis or sodium hyaluronate $[15,20-22]$, with only limited efficacy. Radiotherapy $[23,24]$ and treatment with human recombinant interferon- $\gamma[25]$ and D-penicillamine $[26,27]$ also demonstrated little efficacy. Surgery aiming to remove peridural fibrosis was abandoned because of poor mid- and long-term outcomes, and the high incidence of adverse events [2, 28-31]. The most frequently used treatment is intradural [32] or peridural corticosteroid injections [33]. However, controlled trials addressing their efficacy in the setting of sciatica pain associated with post-operative peridural lumbar fibrosis are lacking. Only one randomized controlled study compared the efficacy of forceful peridural corticosteroid injections via the sacral hiatus to simple peridural corticosteroid injections on sciatica pain ascribed to post-operative lumbar spinal fibrosis. At 6-month follow-up, the proportion of patients with sciatica relief was significantly higher with forceful than simple injection (29 (45\%) versus 31 (19\%); $p=0.03$ ) [34].

Recently, cytokine inhibitors have generated intense interest as a possible treatment for radiculopathy. The inflammatory cytokine tumor necrosis factor (TNF)- $\alpha$ promotes the production of pro-inflammatory soluble mediators, angiogenic factors and chemokines by various cell types and tissues [35]. TNF- $\alpha$ also promotes tissue fibrosis by stimulating fibroblast proliferation and modulating their chemotaxis [36]. In addition, TNF- $\alpha$ blockade with anti-TNF- $\alpha$ monoclonal antibodies has demonstrated some efficacy in conditions associated with tissue fibrosis [37]. In murine models of lung fibrosis induced by bleomycin or silicium oxide particles, the TNF- $\alpha$ level was increased in lung tissue. TNF- $\alpha$ injection induced changes mimicking those observed in lung fibrosis, such as increased number of fibroblasts, collagen deposits and necrosis. Conversely, treatment with TNF- $\alpha$ blockers significantly reduced lung fibrosis [38, 39]. Consistently, TNF- $\alpha$ played an important role in a porcine bronchial model of obliterative bronchiolitis with fibrosis, and its blockade was associated with decreased lesions [40]. Most recently, topical application of etanercept, a TNF- $\alpha$ blocker, was effective in reducing epidural fibrosis in rats after laminectomy [41].

Altogether, clinical and experimental data suggest a pathogenic role of TNF- $\alpha$ in scar formation and fibrotic processes. We hypothesized that blocking TNF- $\alpha$ may be of interest in management of post-operative peridural lumbar fibrosis, and we aimed to assess the efficacy and safety of TNF- $\alpha$ inhibition with infliximab (IFX) on the associated sciatica pain 10 days after the treatment.

\section{Methods}

\section{Design}

We conducted a parallel-group, double-blind, randomized placebo-controlled monocentric study in a tertiary care hospital (Cochin Hospital, Paris, France).

\section{Patient selection}

Patients referred to our rehabilitation department for recurrent sciatica after discectomy were screened. Inclusion criteria were age $>18$ years old, sciatica postdiscectomy, radicular pain measured on a visual analog scale (VAS) $>40 \mathrm{~mm}$ and inability to perform usual activities, surgical discectomy (between 2 years and 6 months 
previously), pain-free between 1 month and 1 year after the discectomy, MRI with gadolinium injection $<6$ months and performed $>6$ months after the discectomy, presence of peridural fibrosis on MRI, and failure of peridural injection treatment. Exclusion criteria were untreated chronic psychiatric disorders, presence of a conflict between the nerve root and herniated disc or disc fragments or spinal stenosis, severe cognitive impairment, inability to understand and speak French, enrollment in another clinical trial in the previous 3 months, and contraindications to IFX treatment including previous allergic reactions to IFX or its components, classes III or IV cardiac failure, active or latent tuberculosis evidenced by clinical examination, tuberculin intra-dermal reaction and chest X-ray, severe infections, pregnancy, breastfeeding, absence of contraception for women, and cancer $<5$ years.

\section{Patient characteristics at baseline}

The following parameters were recorded for each patient at baseline: age; sex; height; weight; retirement and sick leave status; lumbar, radicular and neuropathic pain on a VAS (0-100 mm); Québec disability score (20 items; scored from $0=$ no disability to $5=$ impossible to do; final score 0-100); self-reported clinically significant symptoms of anxiety or depression by the Hospital Anxiety and Depression Scale (HAD-S; seven items related to anxiety and seven to depression; each item scored on a scale from 0 to 3 ; total score ranging from $0=$ no depression, no anxiety to $21=$ maximal depression, maximal anxiety), the Fear-Avoidance Beliefs Questionnaire score (FAB-Q; five items related to physical activity and seven to work; each item scored on a scale from $0=$ "do not at all agree" to $6=$ "completely agree"; total score ranging from $0=$ low fear-avoidance beliefs to 24 for the physical activity dimension or 42 for the work dimension, maximal fear-avoidance beliefs); number of lumbar surgeries; time between surgery and recurrent radicular pain; time between surgery and inclusion; and co-interventions.

\section{MRI examination}

All patients had a lumbar MRI with T1, T2 and T1 with gadolinium injection sequences. Lumbar MRI findings were examined independently by a blinded assessor at baseline for the following parameters: presence or absence of a retractile scar, nerve root enhancement, nerve root enlargement, arachnoiditis, and Modic 1 vertebral endplate subchondral bone changes.

\section{Intervention}

The IFX group received a single intravenous infusion of $3 \mathrm{mg} / \mathrm{kg}$ IFX (REMICADE, Schering-Plough Centocor, B.V., AMM n ${ }^{\circ}$ EU/1/99/116/001; CIP 562 070.1) over a 2-hour period, with vital signs assessed by a physician for the first 10 minutes, then by a nurse for the rest of the infusion time and for an additional 2 hours. The placebo group received a single saline serum infusion (9\% sodium chloride, Maco Pharma) over a 2-hour period, with vital signs assessed by a physician for the first 10 minutes, then by a nurse for the rest of the infusion time and for an additional 2 hours. Co-interventions were allowed and recorded. Unauthorized co-interventions were immunosuppressants.

\section{Outcome measures}

The primary outcome was $50 \%$ reduction in sciatica pain measured on a VAS $(0-100 \mathrm{~mm})$ at day 10 . Secondary outcomes were sciatica pain assessed by a VAS at 2 hours and days 30, 90 and 180; lumbar pain assessed by a VAS at 2 hour sand days 10, 30, 90 and 180; patient acceptable symptom state (PASS) defined as a VAS score $<40 \mathrm{~mm}$; and absolute and relative minimum clinically important improvement (MCII) defined as a reduction in VASassessed pain $\geq 15 \mathrm{~mm}$ or $\geq 20 \%$, respectively, at 2 hours and day 10; Québec disability score; co-interventions; and tolerance at days $0,10,30,90$ and 180 .

\section{Tolerance}

Adverse effects during infusion or during follow-up, such as anaphylaxis, fatigue, chest pain, dyspnea, headache, vertigo, dizziness, abdominal pain, nausea, diarrhea, dyspepsia, liver test abnormalities, rash, flush, pruritus, urticaria, skin dryness, increased sweating, respiratory tract infections, sinusitis, and viral infection were recorded. In the case of a reaction to infusion, infusion speed was reduced.

\section{Sample size}

To achieve a $50 \%$ reduction in sciatica VAS pain score between IFX and placebo groups, with an $\alpha$ risk of 0.05 , a power $(1-\beta)$ of 0.80 , and predicted improvement in pain scores of $10 \%$ in the placebo group and $60 \%$ in the IFX group, the number of participants needed was 17 in each group (two-sided chi-square test). With an estimated $10 \%$ of patients lost to follow-up or presenting latent or active tuberculosis, we sought to include 20 patients in each group.

\section{Randomization and allocation concealment}

Patients who met the inclusion criteria and agreed to participate were randomly assigned to the IFX or placebo group. The randomization process was centralized at the coordinating office (Unité de Recherche Clinique, Cochin Hospital), which had no involvement in the enrollment, follow-up, or assessment of participants. A statistician produced a computer-generated randomization list at the coordinating office with block size of 4 . Once the screening process was complete, the investigator sent a 
fax to the coordinating office. The coordinating office randomly assigned the patient to a treatment and faxed the investigator the allocated treatment. IFX and placebo doses were prepared by the pharmacy of the hospital according to the randomization list.

\section{Blinding}

Patients and assessors were blinded to the treatment assigned. Presentations, treatment administration and clinical monitoring of the treatments were strictly identical for each patient. Labeling was anonymized by the pharmacy.

\section{Statistical analysis}

Data analysis involved the use of SAS 9.3 (SAS Institute, Cary, NC, USA). Blinded statisticians (MBB, SG and LQ) performed the statistical analyses at an independent center (Unité de Biostatistique et d'Épidémiologie, Hôtel Dieu, GH Cochin). All analyses were performed on an intent-to-treat basis, in that all patients were considered in the analysis and were analyzed in the group to which they had been assigned. Treatment of missing data involved the last-observation-carried-forward method. For descriptive analyses, qualitative variables are reported with absolute and relative frequencies, and quantitative variables with median (interquartile range (IQR)). For comparative analysis, qualitative variables were compared by chi-square test or Fisher's exact test in cases of low frequency of the observed event. Quantitative variables were compared by Student $t$ test or nonparametric Wilcoxon Mann-Whitney test if the samples were insufficient. VAS at day 10 was also compared quantitatively using an analysis of covariance (ANCOVA) to control for baseline VAS measure imbalanced between treatment groups.

\section{Ethics approval}

In accordance with L.1123-6 article of the French Health Code, the study protocol was submitted and approved by the local ethics committee (Comité consultatif de Protection des Personnes en Recherche Biomédicale de l'Île-de-France). All patients gave written informed consent to participate.

\section{Role of the funding source}

The Assistance Publique-Hôpitaux de Paris (Project no. P050312) funded the study. The funding source was not involved in the design or conduct of the study or collection, management, and analysis of the data. It was not involved in the writing or final approval of the manuscript. Authors did not receive compensation or funding for conducting independent data analyses. The corresponding author had full access to all the data in the study and takes responsibility for the integrity of the data and the accuracy of the data analysis.

\section{Results}

\section{Patient recruitment}

In total, 38 patients met the inclusion criteria; two were excluded because of evidence of tuberculosis during the screening. From February 2007 to December 2011, we randomly assigned 18 patients to the placebo group and 18 to the IFX group. One patient was lost to follow-up in the placebo group (withdrew after randomization and before treatment) and none in the IFX group. Overall, data were available for analysis for 17 patients in the placebo group and 18 in the IFX group (Fig. 1).

\section{Baseline characteristics of patients}

The median age was 44.0 years (range 38.0-8.3 years), and the male:female ratio was $1: 1 ; 31$ patients $(88.6 \%)$

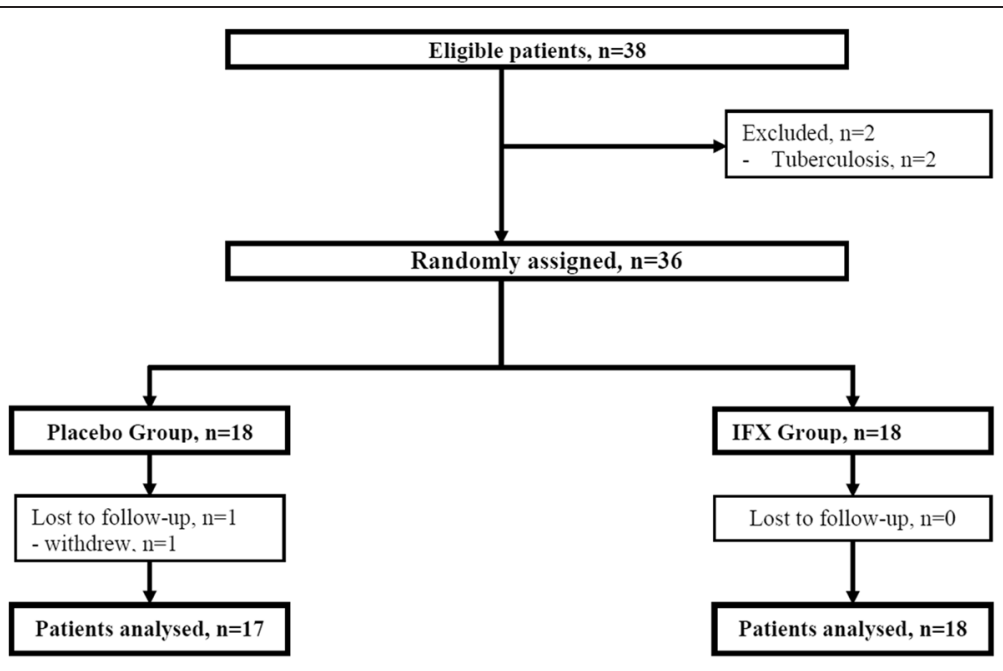

Fig. 1 Flow of patients in the trial. IFX Infliximab 
were on sick leave at the time of inclusion (Table 1). The median Québec score was 48.0 (37.0-63.0). Patients underwent from one to four lumbar surgeries before inclusion, with a median (IQR) time between surgery and recurrent radicular pain of 92.0 (61.0-153.0) days, and a median (IQR) time between the last surgery and inclusion of $2.3(1.6-3.6)$ years. Cointerventions included analgesics, nonsteroidal anti-

Table 1 Patient demographics, low back pain characteristics, and MRI features at baseline

\begin{tabular}{|c|c|c|c|}
\hline & $\begin{array}{l}\text { IFX group } \\
n=18\end{array}$ & $\begin{array}{l}\text { Placebo group } \\
\mathrm{n}=17\end{array}$ & $\begin{array}{l}\text { All patients } \\
\mathrm{n}=35\end{array}$ \\
\hline Age (years), median (IQR) & $45.0(38.0-52.0)$ & $43.0(40.0-48.0)$ & $44.0(38.0-8.3)$ \\
\hline Male sex, n (\%) & $11(61.1)$ & $7(41.2)$ & $18(51.4)$ \\
\hline $\mathrm{BMI}\left(\mathrm{kg} / \mathrm{m}^{2}\right)$, median $(\mathrm{IQR})$ & $27.9(24.8-29.8)$ & $25.8(23.0-29.0)$ & $26.9(24.4-29.8)$ \\
\hline Retired, n (\%) & $0(0)$ & $0(0)$ & $0(0)$ \\
\hline Sick leave, n (\%) & $16(88.9)$ & $15(88.2)$ & $31(88.6)$ \\
\hline Lumbar pain (VAS (0-100 mm)), median (IQR) & $60.0(41.0-80.0)$ & $50.0(26.0-60.0)$ & $58.0(35.0-70.0)$ \\
\hline Radicular pain, (VAS (0-100 mm)), median (IQR) & $70.0(65.0-85.0)$ & $55.0(50.0-70.0)$ & $65.0(45.0-76.0)$ \\
\hline Neuropathic pain, n (\%) & $18(100)$ & $11(64.7)$ & $29(82.9)$ \\
\hline Neuropathic pain (VAS (0-100 mm)), median (IQR) & $62.5(40.0-75.0)$ & $45.0(41.0-75.0)$ & $50.0(41.0-70.0)$ \\
\hline Québec score (0-100), median (IQR) & $55.0(37.0-68.0)$ & $45.0(31.0-62.0)$ & $48.0(37.0-63.0)$ \\
\hline \multicolumn{4}{|l|}{ HAD-S, median (IQR) } \\
\hline HAD anxiety score (0-21) & $10.0(6.0-15.0)$ & $10.0(8.0-14.0)$ & $10.0(6.0-14.0)$ \\
\hline HAD depression score $(0-21)$ & $9.0(6.0-11.0)$ & $7.0(5.0-9.0)$ & $7.5(6.0-11.0)$ \\
\hline \multicolumn{4}{|l|}{ FAB-Q, median (IQR) } \\
\hline FAB-Q work subscale score $(0-42)$ & $33.0(21.0-41.0)$ & $24.0(19.0-35.0)$ & $30.0(20.0-39.0)$ \\
\hline FAB-Q physical activity subscale score (0-24) & $14.0(11.0-19.0)$ & $16.0(10.0-19.0)$ & $14.0(10.0-20.0)$ \\
\hline \multicolumn{4}{|l|}{ Number of lumbar surgeries, $\mathrm{n}(\%)$} \\
\hline 1 & $9(50.0)$ & $4(23.5)$ & $13(37.1)$ \\
\hline 2 & $3(16.7)$ & $9(52.9)$ & $12(34.3)$ \\
\hline 3 & $4(22.2)$ & $3(17.7)$ & $7(20.0)$ \\
\hline 4 & $2(11.1)$ & $1(5.9)$ & $3(8.6)$ \\
\hline Time between surgery and recurrent radicular pain (days), median (IQR) & $77.0(46.0-142.0)$ & $99.0(91.0-153.0)$ & $92.0(61.0-153.0)$ \\
\hline Time between last surgery and inclusion (years), median (IQR) & $1.9(1.4-3.0)$ & $2.7(1.8-4.5)$ & $2.3(1.6-3.6)$ \\
\hline Co-interventions, n (\%) & $15(83.3)$ & $15(88.2)$ & $30(85.7)$ \\
\hline Analgesics & $14(77.8)$ & $15(88.2)$ & $29(82.9)$ \\
\hline Grade 1 & $9(50.0)$ & $8(47.1)$ & $17(48.6)$ \\
\hline Grade 2 & $12(66.7)$ & $11(64.7)$ & $23(65.7)$ \\
\hline Grade 3 & $2(11.1)$ & $1(5.9)$ & $3(8.6)$ \\
\hline Nonsteroidal anti-inflammatory drugs & $5(27.8)$ & $5(29.4)$ & $10(28.6)$ \\
\hline Corticosteroids & $2(11.1)$ & $2(11.8)$ & $4(11.4)$ \\
\hline Antidepressants & $9(50.0)$ & $11(64.7)$ & $20(57.1)$ \\
\hline Anxiolytics & $3(16.7)$ & $3(17.6)$ & $6(17.1)$ \\
\hline Antiepileptics & $8(44.4)$ & $8(47.1)$ & $16(45.7)$ \\
\hline Retractile scar, n (\%) & $13(72.2)$ & $10(58.8)$ & $23(65.7)$ \\
\hline Nerve root enhancement, n (\%) & $14(77.8)$ & $11(64.7)$ & $25(71.4)$ \\
\hline Nerve root enlargement, $\mathrm{n}(\%)$ & $11(61.1)$ & $4(23.5)$ & $15(42.9)$ \\
\hline Arachnoiditis, n (\%) & $3(16.7)$ & $2(11.8)$ & $5(14.3)$ \\
\hline Modic 1 changes, n (\%) & $10(55.6)$ & $9(52.9)$ & $19(54.3)$ \\
\hline
\end{tabular}


inflammatory drugs, corticosteroids, antidepressants, anxiolytics and antiepileptics, and were found in 30 patients $(85.7 \%)$. The most frequent MRI lumbar feature was nerve-root enhancement, seen in 25 patients (71.4 \%), followed by presence of a retractile scar in 23 (65.7\%). Modic 1 vertebral endplate subchondral bone changes detected by MRI were present in 19 patients $(54.3 \%)$ in total.

\section{Primary outcome}

The placebo and IFX group did not differ in the primary outcome: at day 10 , three $(17.6 \%)$ versus five $(27.8 \%)$ patients showed a $50 \%$ reduction in sciatica pain $(p=0.69$; Table 2).

\section{Secondary outcomes}

In the intent-to-treat analysis, between baseline and 10 days, the median (IQR) absolute change in radicular VAS pain score in the placebo and IFX group was $0.0(-30.9$ to -10.0$)$ and $-14.9(-50.0$ to -3.3$) \mathrm{mm}$, respectively $(p=0.21)$ and the median absolute change in lumbar VAS pain score was 16.7 (-16.7 to -34.6$)$ and $-6.0(-20.0$ to -2.9$) \mathrm{mm}$, respectively (Fig. 2). When adjusting for baseline VAS radicular pain score, the ANCOVA analysis did not reveal any treatment effect (data not shown). The two groups did not differ in all other secondary outcomes, except for number of patients reaching the PASS for radicular pain (VAS $<40 \mathrm{~mm}$ ), which was significantly higher for the placebo than IFX group at day 0 after injection (12 (70.6\%) versus five $(27.8 \%) ; p=0.01$; Table 2). Overall, radicular and lumbar pain and disability scores remained stable over time in both groups (Tables 2 and 3). No drug-sparing effect was observed in the IFX group compared to the placebo group, whatever the co-intervention assessed (Appendix 1).

\section{Safety}

Overall, 128 adverse events were reported, 65 in the placebo group and 63 in the IFX group, but none was considered serious or related to treatment. The most frequently reported adverse events were increased radicular pain, infections, gastrointestinal symptoms, joint pain and respiratory symptoms, and were observed in $51.4 \%$, $80.0 \%, 40.0 \%, 34.3 \%$, and $20.0 \%$ of patients, respectively, with no significant difference between the two treatment groups (Appendix 2).

\section{Discussion}

TNF- $\alpha$ could be a key pro-inflammatory and pro-fibrotic cytokine in the genesis of post-operative peridural fibrosis and subsequent painful symptoms. In this double-blind, randomized controlled trial, we assessed the efficacy and safety of TNF- $\alpha$ blockade with a single intravenous injection of IFX, $3 \mathrm{mg} / \mathrm{kg}$, in managing sciatica pain due to post-operative peridural lumbar fibrosis. A single 3-mg/kg IFX injection had no clinically significant effect on sciatica pain as compared with placebo at day 10. The number of patients reaching the PASS for radicular pain was significantly higher in the placebo than IFX group at 2 hours after injection. In addition, ANCOVA revealed that the changes in radicular VAS pain at days 0 and 10 after injection were explained by radicular VAS pain at baseline rather than a treatment effect (estimated coefficient 0.77 (95\% confidence interval 0.25-1.30), $p=0.01$, and 0.87

Table 2 Change in radicular pain at days 0 and 10 after injection

\begin{tabular}{|c|c|c|c|c|}
\hline \multirow[t]{2}{*}{ Outcomes } & IFX group & Placebo group & All patients & \multirow[t]{2}{*}{$p$-value } \\
\hline & $\mathrm{n}=18$ & $\mathrm{n}=17$ & $n=35$ & \\
\hline \multicolumn{5}{|l|}{ Day 0 after injection } \\
\hline Absolute VAS change, median (IQR) & $-26.8(-54.8$ to -14.3$)$ & $-56.7(-73.3$ to -28.6$)$ & $-36.0(-72.3$ to -14.3$)$ & 0.22 \\
\hline $50 \%$ reduction in sciatica pain, $\mathrm{n}(\%)$ & $5(27.8)$ & $9(52.9)$ & $14(40.0)$ & 0.13 \\
\hline PASS <40 mm, n (\%) & $5(27.8)$ & $12(70.6)$ & $17(48.6)$ & $0.01^{*}$ \\
\hline $\mathrm{MCl} \geq 15 \mathrm{~mm}, \mathrm{n}(\%)$ & $12(66.7)$ & $13(76.5)$ & $25(71.4)$ & 0.52 \\
\hline $\mathrm{MCl} \geq 20 \%, \mathrm{n}(\%)$ & $11(61.1)$ & $13(76.5)$ & $24(68.6)$ & 0.33 \\
\hline \multicolumn{5}{|l|}{ Day 10 after injection } \\
\hline Absolute VAS change, median (IQR) & $-14.9(-50.0$ to 3.3$)$ & $0.0(-30.9$ to 10.0$)$ & $-9.2(-38.5$ to 9.1$)$ & 0.21 \\
\hline $50 \%$ reduction in sciatica pain, $\mathrm{n}(\%)$ & $5(27.8)$ & $3(17.6)$ & $8(22.9)$ & 0.69 \\
\hline PASS <40 mm, n (\%) & $4(22.2)$ & $4(23.5)$ & $8(22.9)$ & 0.94 \\
\hline $\mathrm{MCl} \geq 15 \mathrm{~mm}, \mathrm{n}(\%)$ & $9(50.0)$ & $5(29.4)$ & $14(40.0)$ & 0.21 \\
\hline $\mathrm{MCI} \geq 20 \%, \mathrm{n}(\%)$ & $8(44.4)$ & $5(29.4)$ & $13(37.1)$ & 0.36 \\
\hline
\end{tabular}



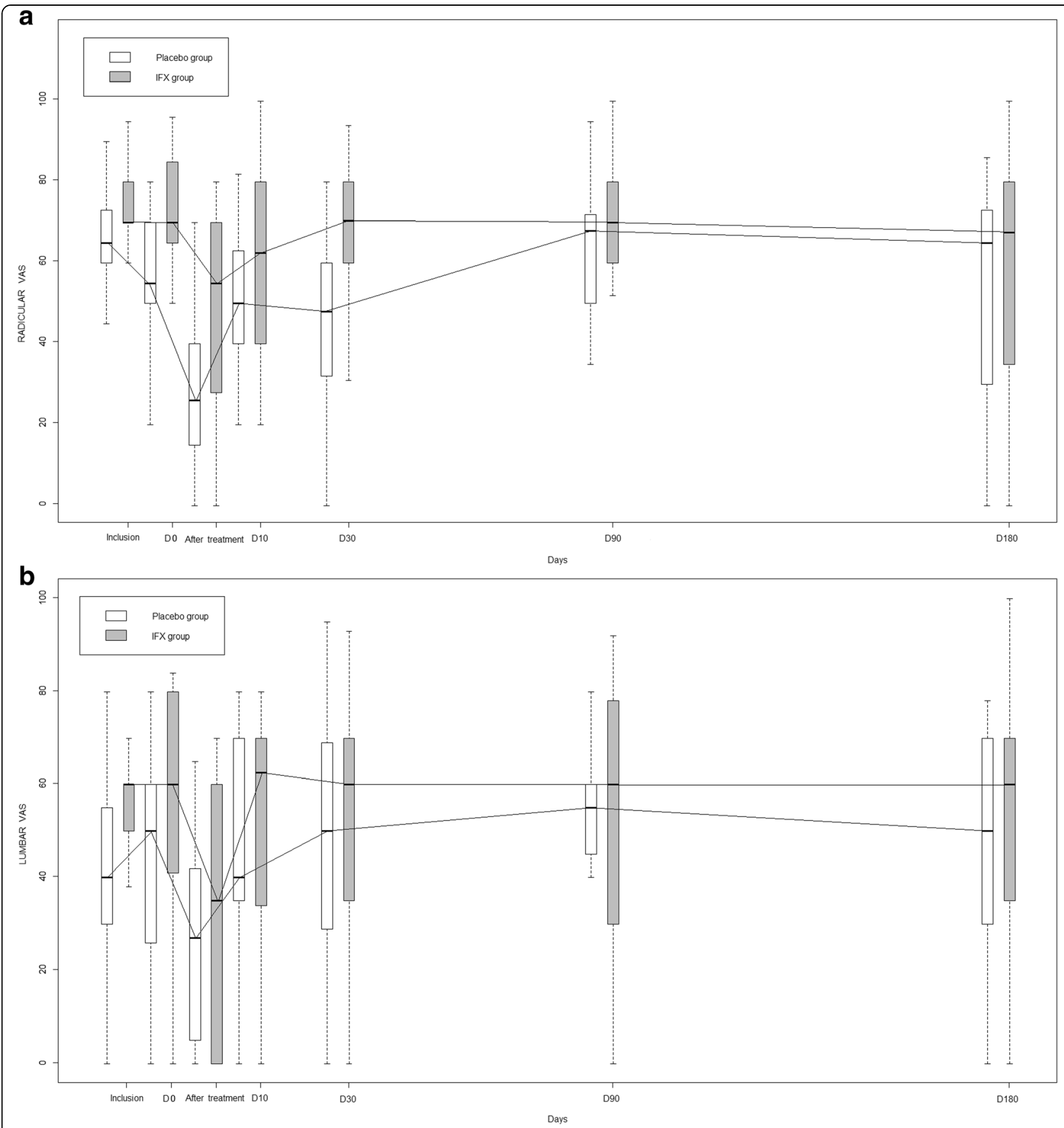

Fig. 2 Changes in a radicular and $\mathbf{b}$ lumbar pain scores measured on a visual analog scale over time in patients receiving infliximab and placebo. Box-and-whisker plots represent results expressed in median and interquartile range

(0.40-1.34), $p<0.001$, respectively; data not shown). Overall, the treatment was well tolerated, and no serious adverse events related to the treatment occurred during the study period.

Several hypotheses could explain the lack of efficacy of a potent active treatment in a randomized controlled trial, including a high placebo effect or spontaneous improvement resulting in sustained beneficial effects in all treatment groups, the design of the study, insufficient dose and the lack of efficacy of the drug or the importance of imbalance of baseline VAS.

Intravenous injection is commonly associated with a powerful placebo effect that can persist for months or even years and limits the ability to detect effects specific to the treatment [42]. Consistent with previous reports of an early placebo effect of saline infusion on sciatica pain $[43,44]$, 
Table 3 Radicular and lumbar pain scores and Québec disability score during follow-up

\begin{tabular}{|c|c|c|c|}
\hline \multirow[t]{2}{*}{ Time points } & IFX group & Placebo group & All patients \\
\hline & $n=18$ & $n=17$ & $n=35$ \\
\hline \multicolumn{4}{|c|}{ Radicular pain, VAS score $(0-100 \mathrm{~mm})$} \\
\hline Day 0 & $70.0(65.0-85.0)^{*}$ & $55.0(50.0-70.0)$ & $70.0(55.0-80.0)$ \\
\hline Day 0 post-injection & $55.0(28.0-70.0)$ & $26.0(15.0-40.0)$ & $40.0(18.0-60.0)$ \\
\hline Day 10 & $62.5(40.0-80.0)$ & $50.0(40.0-63.0)$ & $58.0(40.0-75.0)$ \\
\hline Day 30 & $70.5(60.0-80.0)$ & $48.0(32.0-60.0)$ & $60.0(40.0-75.0)$ \\
\hline Day 90 & $70.0(60.0-80.0)$ & $68.0(50.0-72.0)$ & $68.0(52.0-78.0)$ \\
\hline Day 180 & $67.5(45.0-80.0)$ & $65.0(30.0-73.0)$ & $65.0(35.0-80.0)$ \\
\hline \multicolumn{4}{|c|}{ Lumbar pain, VAS score (0-100 mm) } \\
\hline Day 0 & $60.0(41.0-80.0)$ & $50.0(26.0-60.0)$ & $55.0(35.0-70.0)$ \\
\hline Day 0 post-injection & $35.0(0.0-60.0)$ & $27.0(5.0-42.0)$ & $30.0(0.0-60.0)$ \\
\hline Day 10 & $62.5(34.0-70.0)$ & $40.0(35.0-70.0)$ & $60.0(34.0-70.0)$ \\
\hline Day 30 & $60.0(35.0-70.0)$ & $55.0(30.0-69.0)$ & $60.0(30.0-70.0)$ \\
\hline Day 90 & $60.0(30.0-78.0)$ & $55.0(45.0-60.0)$ & $55.0(40.0-70.0)$ \\
\hline Day 180 & $60.0(35.0-70.0)$ & $50.0(30.0-70.0)$ & $60.0(32.0-70.0)$ \\
\hline \multicolumn{4}{|c|}{ Québec disability score (0-100) } \\
\hline Day 0 & $55.0(37.0-68.0)$ & $45.0(31.0-62.0)$ & $51.0(37.0-65.0)$ \\
\hline Day 10 & $51.5(39.0-66.0)$ & $48.0(39.0-55.0)$ & $51.0(39.0-59.0)$ \\
\hline Day 30 & $57.5(38.0-67.0)$ & $45.0(33.0-55.0)$ & $47.0(34.0-66.0)$ \\
\hline Day 90 & $53.5(38.0-69.0)$ & $44.5(36.0-53.5)$ & $46.5(38.0-64.0)$ \\
\hline Day 180 & $53.5(37.0-70.0)$ & $44.0(34.0-51.0)$ & $48.0(34.0-60.0)$ \\
\hline
\end{tabular}

Data are median (interquartile range)

IFX Infliximab, VAS Visual analog scale

${ }^{*} \mathrm{p}<0.05$ compared to placebo group

our study showed a powerful immediate placebo effect, as suggested by the early and strong improvement in radicular and lumbar pain scores as well as a higher rate of patients reaching the PASS in the placebo than IFX group at 2 hours after injection. Korhonen et al, assessed the efficacy of IFX compared to saline in sciatica by disk herniation; approximately $15 \%$ of the patients in the saline group had an immediate reduction of at least $75 \%$ of sciatica pain at day 0 $[43,44]$. In our study, the immediate placebo effect may have been greater in the saline group than in the IFX group. However, determinants of this early placebo effect of intravenous injections have not been clearly identified yet. At day 10, we did not observe a high placebo response that may have skewed the results for our primary outcome: the median (IQR) absolute change in radicular VAS pain score for the placebo and IFX group was 0.0 (-30.9 to 10.0) and $-14.9(-50.0$ to 3.3$) \mathrm{mm}$, respectively $(p=0.21)$. Contrary to what has been previously reported in acute or subacute disk herniation-induced sciatica pain [45], we found no significant spontaneous improvement over time for leg pain, back pain or disability, which therefore did not interfere with the treatment effect. The stability of symptoms over the 180-day follow-up is most likely explained by the chronicity of the fibrotic changes with a median (IQR) duration time between last lumbar surgery and inclusion of $2.3(1.6-3.6)$ years and by the severity of the condition, with high levels of disability and failure of previous treatments. Moreover, fibrotic processes encompass various stages. In the earliest stages, local inflammation is thought to play an important role but might not be important later on. Therefore, there might be a therapeutic window of opportunity for anti-inflammatory treatment in the fibrotic process.

For the intervention group, IFX may not have been administered at the optimal therapeutic dose or the exposure duration to the drug may not have been long enough. The dosing regimen we used was based on previous published studies addressing the efficacy of intravenous IFX for treatment of acute or subacute disk herniation-induced sciatica pain [46] designed with a single injection of $3 \mathrm{mg} / \mathrm{kg}[47,48]$ or $5 \mathrm{mg} / \mathrm{kg}$ IFX [43, 44]. This design might not have been appropriate for a more chronic inflammatory condition such as peridural fibrosis. Indeed, in chronic inflammatory conditions, such as rheumatoid arthritis, a dose optimization is recommended every 8 weeks, starting from $3 \mathrm{mg} / \mathrm{kg}$ [49]. However, in the absence of previously published data, and considering the balance of risks and benefits of TNF- $\alpha$ blockade, we did not optimize the IFX dose and 
used a single injection at the lower dose. Furthermore, despite some experimental and clinical evidence, targeting TNF- $\alpha$ in late-stage fibrotic processes might not be efficient. Only small studies assessed the efficacy of IFX in fibrosis-associated human diseases including primary sclerosing cholangitis and pulmonary fibrosis associated with collagen vascular disease and failed to demonstrate a clear benefit $[50,51]$.

In our study, the prevalence of Modic 1 vertebral endplate subchondral bone changes was high in both groups (55.6 \% in the IFX group versus $52.9 \%$ in the placebo group). Modic 1 changes have been reported to be biomarkers of a subset of nonspecific chronic low back pain patients who display a particular clinical, biological and MRI phenotype, leading to the concept of 'active discopathy' [52]. The role of local inflammation in the pathogenesis of active discopathy has been suggested, with studies reporting the efficacy of local treatment with intradiscal anti-inflammatory drugs on lumbar pain $[53,54]$. However, we did not observe any differences between the two groups on lumbar pain. Hypotheses to explain the lack of efficacy of anti-TNF- $\alpha$ therapy on lumbar pain are the same as above. In addition, one can hypothesize that TNF- $\alpha$ might not be central in generating active discopathy-related Modic 1 signal and back pain symptoms, as suggested by animal models $[55,56]$.

Some factors may limit the generalizability of our findings. Selecting inclusion and exclusion criteria is challenging in chronic pain studies. The refractoriness to treatment among patients with a longer duration of symptoms and significant coexisting psychopathology is likely to result in lower response rates for treatment participants $[57,58]$. However, in our study, clinically significant symptoms of anxiety and depression assessed by the HAD-S, fearavoidance beliefs by the FAB-Q and coping strategies by the Coping Strategies Questionnaire (data not shown) were comparable between the two treatment groups over time. Finally, one of the major challenges of this trial was to enroll a sufficient number of patients. One can hypothesize that the latest improvements in surgical techniques in the past decade have led to a reduction in the extent of peridural fibrotic scar, and to a decreased prevalence of failed back surgery syndrome associated with this condition.

\section{Conclusions}

This randomized controlled trial did not demonstrate a clinically significant effect of a single intravenous injection of IFX at $3 \mathrm{mg} / \mathrm{kg}$. However, from our knowledge of the pathogenesis of pain, targeting local chronic inflammation and fibrotic processes closely related to painful symptoms might still be relevant for managing this condition. We cannot conclude whether a higher dose or longer or earlier exposure to the drug would have provided more benefit, and therefore we cannot recommend the clinical use of TNF- $\alpha$ blockade for recurrent chronic sciatica pain associated with peridural fibrosis. Further studies are warranted to confirm our results and to address the effects of other anti-inflammatory or antifibrotic agents with dose optimization.

\section{Appendix 1}

Table 4 Co-interventions during follow-up

\begin{tabular}{|c|c|c|c|}
\hline Timepoints & IFX Group n=18 & Placebo group $n=17$ & Total $n=35$ \\
\hline & \multicolumn{3}{|c|}{ Analgesics } \\
\hline Day 0 & $14(77.8)$ & $15(88.2)$ & $29(82.9)$ \\
\hline Day 10 & $14(77.9)$ & $16(94.1)$ & $30(85.7)$ \\
\hline Day 30 & $15(83.3)$ & $16(94.1)$ & $31(88.6)$ \\
\hline Day 90 & $14(77.8)$ & $16(94.1)$ & $30(85.7)$ \\
\hline \multirow[t]{2}{*}{ Day 180} & $15(83.3)$ & $15(88.2)$ & $30(85.7)$ \\
\hline & \multicolumn{3}{|c|}{ Non-steroidal anti-inflammatory drugs } \\
\hline Day 0 & $5(27.8)$ & $5(29.4)$ & $10(28.6)$ \\
\hline Day 10 & $5(27.8)$ & $7(41.2)$ & $12(34.3)$ \\
\hline Day 30 & $5(27.8$ & $6(35.3)$ & $11(31.4)$ \\
\hline Day 90 & $6(33.3)$ & $6(35.3)$ & $12(34.3)$ \\
\hline \multirow[t]{2}{*}{ Day 180} & $5(27.8)$ & $5(29.4)$ & $10(28.6)$ \\
\hline & \multicolumn{3}{|c|}{ Corticosteroids } \\
\hline Day 0 & $2(11.1)$ & $2(11.8)$ & $4(11.4)$ \\
\hline Day 10 & $2(11.1)$ & $2(11.8)$ & $4(11.4)$ \\
\hline Day 30 & $2(11.1)$ & $2(11.8)$ & $4(11.4)$ \\
\hline Day 90 & $2(11.1)$ & $2(11.8)$ & $4(11.4)$ \\
\hline \multirow[t]{2}{*}{ Day 180} & $2(11.1)$ & $2(11.8)$ & $4(11.4)$ \\
\hline & \multicolumn{3}{|c|}{ Antidepressants } \\
\hline Day 0 & $9(50.0)$ & $11(64.7)$ & $20(57.1)$ \\
\hline Day 10 & $11(61.1)$ & 12 (70.6) & $23(65.7)$ \\
\hline Day 30 & $10(55.6)$ & $12(70.6)$ & $22(62.9)$ \\
\hline Day 90 & $10(55.6)$ & $12(70.6)$ & $22(62.9)$ \\
\hline \multirow[t]{2}{*}{ Day 180} & $9(50.0)$ & $11(64.7)$ & $20(57.1)$ \\
\hline & \multicolumn{3}{|c|}{ Anxiolytics } \\
\hline Day 0 & $3(16.7)$ & $3(17.6)$ & $6(17.1)$ \\
\hline Day 10 & $3(16.7)$ & $4(23.5)$ & $7(20.0)$ \\
\hline Day 30 & $3(16.7)$ & $5(29.4)$ & $8(22.9)$ \\
\hline Day 90 & $3(16.7)$ & $4(23.5)$ & $7(20.0)$ \\
\hline \multirow[t]{2}{*}{ Day 180} & $3(16.7)$ & $3(17.6)$ & $6(17.1)$ \\
\hline & \multicolumn{3}{|c|}{ Antiepileptics } \\
\hline Day 0 & $8(44.4)$ & $8(47.1)$ & $16(45.7)$ \\
\hline Day 10 & $10(55.6)$ & $11(64.7)$ & $21(60.0)$ \\
\hline Day 30 & $10(55.6)$ & $10(58.8)$ & $20(57.1)$ \\
\hline Day 90 & $9(50.0)$ & $9(52.9)$ & $18(51.4)$ \\
\hline Day 180 & $8(44.4)$ & $8(47.1)$ & $16(45.7)$ \\
\hline
\end{tabular}

Data are absolute frequencies (\%). 


\section{Appendix 2}

Table 5 Adverse events recorded $<10$ and $\geq 10$ days during follow-up.

\begin{tabular}{|c|c|c|c|c|c|c|c|}
\hline \multirow[t]{2}{*}{ Adverse events } & \multicolumn{2}{|c|}{$<10$ days } & \multicolumn{2}{|l|}{$\geq 10$ days } & \multicolumn{2}{|l|}{ Total } & \multirow[b]{2}{*}{ p-value } \\
\hline & $\mathrm{IFX}$ & PBO & IFX & PBO & $\mathrm{IFX}$ & PBO & \\
\hline Increased neuropathic pain & $0(0)$ & $0(0)$ & $0(0)$ & $1(5.9)$ & $0(0)$ & $1(5.9)$ & - \\
\hline Increased lumbar pain & $0(0)$ & $1(5.9)$ & $0(0)$ & $2(11.8)$ & $0(0)$ & $4(23.5)$ & - \\
\hline Increased radicular pain & $5(27.8)$ & $4(23.5)$ & $3(16.7)$ & $2(11.8)$ & $10(55.6)$ & $8(47.1)$ & 0.56 \\
\hline Headache & $3(16.7)$ & $1(5.9)$ & $2(11.1)$ & $1(5.9)$ & $5(27.8)$ & $2(11.8)$ & - \\
\hline Fatigue & $2(11.1)$ & $0(0)$ & $2(11.1)$ & $1(5.9)$ & $5(27.8)$ & $1(5.9)$ & - \\
\hline Hospitalization & $0(0)$ & $0(0)$ & $0(0)$ & $2(11.8)$ & $0(0)$ & $2(11.8)$ & - \\
\hline Hospitalization for lumbo-radicular pain & $0(0)$ & $0(0)$ & $3(16.7)$ & $1(5.9)$ & $3(16.7)$ & $1(5.9)$ & - \\
\hline Infections & $4(22.2)$ & $1(5.9)$ & $11(56.0)$ & $13(76.4)$ & $14(77.8)$ & $14(82.4)$ & 0.93 \\
\hline Cardiovascular symptoms & $0(0)$ & $1(5.9)$ & $0(0)$ & $1(5.9)$ & $0(0)$ & $2(11.8)$ & - \\
\hline Skin symptoms & $1(5.6)$ & $1(5.9)$ & $1(5.6)$ & $2(11.8)$ & $2(11.1)$ & $3(17.6)$ & - \\
\hline Gastrointestinal symptoms & $2(11.1)$ & $2(11.8)$ & $6(33.3)$ & $4(23.5)$ & $8(44.4)$ & $6(35.3)$ & 0.53 \\
\hline Gynecological symptoms & $0(0)$ & $0(0)$ & $0(0)$ & $2(11.8)$ & $0(0)$ & $2(11.8)$ & - \\
\hline Hormonal manifestations & $2(11.1)$ & $2(11.8)$ & $0(0)$ & $0(0)$ & $2(11.1)$ & $2(11.8)$ & - \\
\hline Joint pain & $2(11.1)$ & $0(0)$ & $4(22.2)$ & $6(35.3)$ & $6(33.3)$ & $6(35.3)$ & 0.95 \\
\hline Psychiatric disorder & $1(5.6)$ & $0(0)$ & $0(0)$ & $1(5.9)$ & $1(5.6)$ & $1(5.9)$ & - \\
\hline Respiratory symptoms & $0(0)$ & $1(5.9)$ & $2(11.1)$ & $4(23.5)$ & $2(11.1)$ & $5(29.4)$ & - \\
\hline Sleeping disorder & $0(0)$ & $0(0)$ & $1(5.6)$ & $1(5.9)$ & $1(5.6)$ & $1(5.9)$ & - \\
\hline Sexual disorder & $0(0)$ & $1(5.9)$ & $15.6)$ & $1(5.9)$ & $1(5.6)$ & $3(17.6)$ & - \\
\hline Traumatism & $0(0)$ & $1(5.9)$ & $0(0)$ & $0(0)$ & $0(0)$ & $1(5.9)$ & - \\
\hline Vertigo & $0(0)$ & $0(0)$ & $3(16.7)$ & $0(0)$ & $3(16.7)$ & $0(0)$ & - \\
\hline Total & 22 & 17 & 38 & 44 & 63 & 65 & - \\
\hline
\end{tabular}

IFX: IFX group; PBO: placebo group.

Data are absolute frequencies (\%).

\section{Abbreviations}

ANCOVA: Analysis of covariance; FAB-Q: Fear-Avoidance Beliefs Questionnaire; HAD-S: Hospital Anxiety and Depression Scale; IFX: Infliximab; IQR: Interquartile range; MCII: minimum clinically important improvement; MRI: Magnetic resonance imaging; PASS: Patient acceptable symptom state; TNF: Tumor necrosis factor; VAS: Visual analog scale.

\section{Competing interests}

The authors declare that they have no competing interests.

\section{Author's contributions}

Conception and design of the study: SG, AF, MR, MMLC, SP, FR. Acquisition of data: CN, CP, AF, KS, NZ, MR, MMLC, SP, FR. Analysis and interpretation of data: all authors. Statistical analysis: CN, CP, SG, LQ, MBB, SP, FR. Manuscript drafting: all authors. Manuscript revision: all authors. All authors read and approved the manuscript.

\section{Funding}

Assistance Publique - Hôpitaux de Paris (Project no. P050312).

\section{Author details}

'Univ. Paris Descartes, PRES Sorbonne Paris Cité, Service de Rééducation et Réadaptation de l'Appareil Locomoteur et des Pathologies du Rachis, Hôpital Cochin, Assistance Publique - Hôpitaux de Paris, Paris, France. ${ }^{2}$ Univ. Paris Descartes, PRES Sorbonne Paris, Cité Laboratoire de Pharmacologie, Toxicologie et Signalisation Cellulaire, INSERM UMR-S 1124, UFR Biomédicale des Saints Pères, Paris, France. ${ }^{3}$ Univ. Paris Descartes, PRES Sorbonne Paris,
INSERM UMR-S 1153 et Institut Fédératif de Recherche sur le Handicap, Paris, France. ${ }^{4}$ Univ. Paris Descartes, PRES Sorbonne Paris, Biostatistics and Epidemiology Unit, Hôtel Dieu, Assistance Publique-Hôpitaux de Paris, Paris, France. ${ }^{5}$ INSERM UMR-S 1136, Institut Pierre Louis d'Épidémiologie et de Santé Publique, F-75013, Paris, France. ${ }^{6}$ Univ. Paris Descartes, PRES Sorbonne Paris Cité, Service de Radiologie B, Hôpital Cochin, Assistance Publique Hôpitaux de Paris, Paris, France.

Received: 22 July 2015 Accepted: 27 October 2015

Published online: 19 November 2015

\section{References}

1. Robertson JT. Role of peridural fibrosis in the failed back: a review. Eur Spine J. 1996;5 Suppl 1:S2-6.

2. Burton CV, Kirkaldy-Willis WH, Yong-Hing K, Heithoff KB. Causes of failure of surgery on the lumbar spine. Clin Orthop Relat Res. 1981;157:191-9.

3. Gabriel EM, Friedman AH. The failed back surgery syndrome. In: Wilkins RH, Rengachary DD, editors. Neurosurgery. New York: McGraw-Hill; 1996.

4. Key JA, Ford LT. Experimental intervertebral-disc lesions. J Bone Joint Surg Am. 1948;30A(3):621-30.

5. Songer MN, Rauschning W, Carson EW, Pandit SM. Analysis of peridural scar formation and its prevention after lumbar laminotomy and discectomy in dogs. Spine (Phila Pa 1976). 1995;20(5):571-80. discussion 579-80.

6. He Y, Revel M, Loty B. A quantitative model of post-laminectomy scar formation. Effects of a nonsteroidal anti-inflammatory drug. Spine (Phila Pa 1976). 1995;20(5):557-63; discussion 579-80. 
7. LaRocca H, Macnab I. The laminectomy membrane. Studies in its evolution, characteristics, effects and prophylaxis in dogs. J Bone Joint Surg Br. 1974;56B(3):545-50.

8. Revel M, Roux C, Chevrot A, Mayoux-Benhamou A, Mathieu A, Amor B. Primary epidural adhesions and lomboradiculalgia by traction. Rev Med Orthop. 1989;16:48-9.

9. Hasue M. Pain and the nerve root. An interdisciplinary approach. Spine (Phila Pa 1976). 1993;18(14):2053-8.

10. Guyer DW, Wiltse LL, Eskay ML, Guyer BH. The long-range prognosis of arachnoiditis. Spine (Phila Pa 1976). 1989;14(12):1332-41.

11. Ross JS. Magnetic resonance imaging of the postoperative spine. Semin Musculoskelet Radiol. 2000;4(3):281-91.

12. Boot DA, Hughes SP. The prevention of adhesions after laminectomy. Adverse results of Zenoderm implantations into laminectomy sites in rabbits. Clin Orthop Relat Res. 1987;215:296-302.

13. Gill GG, Sakovich L, Thompson E. Pedicle fat grafts for the prevention of scar formation after laminectomy. An experimental study in dogs. Spine (Phila Pa 1976). 1979;4(2):176-86.

14. Gill GG, Scheck M, Kelley ET, Rodrigo JJ. Pedicle fat grafts for the prevention of scar in low-back surgery. A preliminary report on the first 92 cases. Spine (Phila Pa 1976). 1985;10(7):662-7.

15. Jacobs RR, McClain O, Neff J. Control of postlaminectomy scar formation: an experimental and clinical study. Spine (Phila Pa 1976). 1980;5(3):223-9.

16. Yong-Hing K, Reilly J, de Korompay V, Kirkaldy-Willis WH. Prevention of nerve root adhesions after laminectomy. Spine (Phila Pa 1976). 1980;5(1):59-64.

17. Lawson KJ, Malycky JL, Berry JL, Steffee AD. Lamina repair and replacement to control laminectomy membrane formation in dogs. Spine (Phila Pa 1976). 1991;16(6 Suppl):S222-226.

18. Lee $\mathrm{CK}$, Alexander H. Prevention of postlaminectomy scar formation. Spine (Phila Pa 1976). 1984:9(3):305-12.

19. Nussbaum CE, McDonald JV, Baggs RB. Use of Vicryl (polyglactin 910) mesh to limit epidural scar formation after laminectomy. Neurosurgery. 1990;26(4):649-54.

20. Kitano T, Zerwekh JE, Edwards ML, Usui Y, Allen MD. Viscous carboxymethylcellulose in the prevention of epidural scar formation. Spine (Phila Pa 1976). 1991;16(7):820-3.

21. Lee HM, Yang KH, Han DY, Kim NH. An experimental study on prevention of postlaminectomy scar formation. Yonsei Med J. 1990;31(4):359-66.

22. Songer MN, Ghosh L, Spencer DL. Effects of sodium hyaluronate on peridural fibrosis after lumbar laminotomy and discectomy. Spine (Phila Pa 1976). 1990;15(6):550-4

23. Bora H, Aykol SV, Akyurek N, Akmansu M, Ataoglu O. Inhibition of epidural scar tissue formation after spinal surgery: external irradiation vs. spinal membrane application. Int J Radiat Oncol Biol Phys. 2001;51(2):507-13.

24. Pourel J, David R, Picard L, Roland J, Montaut J, Gaucher A. Lumbo-sacral arachno-epiduritis. Clinical and etiological aspects. Sem Hôp Paris. 1977;53: 2109-15.

25. Auleley GR, Ravaud P, Revel M, Amor B. Lack of efficacy of interferon gamma in the treatment of post-operative epidural fibrosis. Rev Rhum Ed Fr. 1994;61:770.

26. Grahame R, Clark B, Watson M, Polkey C. Toward a rational therapeutic strategy for arachnoiditis. A possible role for $\mathrm{d}$-penicillamine. Spine (Phila Pa 1976). 1991;16(2):172-5.

27. Roux H, Aquaron R, Gaborit P, Bonnefoy-Cudraz M. Treatment with D-penicillamin of painful lumbar syndrom related to arachnoiditis. Rev Rhum Mal Osteoartic. 1981;48:549-53.

28. Finnegan WJ, Fenlin JM, Marvel JP, Nardini RJ, Rothman RH. Results of surgical intervention in the symptomatic multiply-operated back patient. Analysis of sixty-seven cases followed for three to seven years. J Bone Joint Surg Am. 1979;61(7):1077-82.

29. Kim SS, Michelsen CB. Revision surgery for failed back surgery syndrome. Spine (Phila Pa 1976). 1992;17(8):957-60

30. North RB, Campbell JN, James CS, Conover-Walker MK, Wang H, Piantadosi S, et al. Failed back surgery syndrome: 5-year follow-up in 102 patients undergoing repeated operation. Neurosurgery. 1991;28(5):685-90. discussion 690-1.

31. Waddell G, Kummel EG, Lotto WN, Graham JD, Hall H, McCulloch JA. Failed lumbar disc surgery and repeat surgery following industrial injuries. J Bone Joint Surg Am. 1979;61(2):201-7.

32. Gayrard M, Arlet J, Espagno J, Maneefe G, Latorzeff S. Lumbar arachno-epiduritis. Rev Rhum Mal Osteoartic. 1975;42:739-45.

33. Heyse-Moore GH. A rational approach to the use of epidural medication in the treatment of sciatic pain. Acta Orthop Scand. 1978;49(4):366-70.
34. Revel M, Auleley GR, Alaoui S, Nguyen M, Duruoz T, Eck-Michaud S, et al. Forceful epidural injections for the treatment of lumbosciatic pain with post-operative lumbar spinal fibrosis. Rev Rhum Engl Ed. 1996;63(4):270-7.

35. Beutler B, Cerami A. Tumor necrosis, cachexia, shock, and inflammation: a common mediator. Annu Rev Biochem. 1988;57:505-18.

36. Strieter RM, Lukacs NW, Kunkel SL. Role of adhesion molecules and cytokines in lung transplantation. In: Ward PA, Fantone JC, editors. Role of adhesion molecules and cytokines in lung transplantation. Adhesion molecules and the lung. New York: Marcel Dekker; 1996.

37. Feldmann M, Maini RN. Anti-TNF alpha therapy of rheumatoid arthritis: what have we learned? Annu Rev Immunol. 2001;19:163-96.

38. Piguet PF. Is "tumor necrosis factor" the major effector of pulmonary fibrosis? Eur Cytokine Netw. 1990;1(4):257-8.

39. Piguet PF, Collart MA, Grau GE, Kapanci Y, Vassalli P. Tumor necrosis factor/ cachectin plays a key role in bleomycin-induced pneumopathy and fibrosis. J Exp Med. 1989;170(3):655-63.

40. Alho HS, Maasilta PK, Harjula AL, Hammainen P, Salminen J, Salminen US Tumor necrosis factor-alpha in a porcine bronchial model of obliterative bronchiolitis. Transplantation. 2003;76(3):516-23.

41. Turkoglu E, Tuncer C, Dinc C, Serbes G, Oktay M, Sekerci Z. The effect of etanercept on spinal epidural fibrosis in a postlaminectomy rat model. Turk Neurosurg. 2014;24(4):506-11.

42. Koshi EB, Short CA. Placebo theory and its implications for research and clinical practice: a review of the recent literature. Pain Pract. 2007;7(1):4-20.

43. Korhonen T, Karppinen J, Paimela L, Malmivaara A, Lindgren KA, Bowman C, et al. The treatment of disc-herniation-induced sciatica with infliximab: oneyear follow-up results of FIRST II, a randomized controlled trial. Spine (Phila Pa 1976). 2006;31(24):2759-66.

44. Korhonen T, Karppinen J, Paimela L, Malmivaara A, Lindgren KA, Jarvinen S, et al. The treatment of disc herniation-induced sciatica with infliximab: results of a randomized, controlled, 3-month follow-up study. Spine (Phila Pa 1976). 2005;30(24):2724-8.

45. Cohen SP, White RL, Kurihara C, Larkin TM, Chang A, Griffith SR, et al. Epidural steroids, etanercept, or saline in subacute sciatica: a multicenter, randomized trial. Ann Intern Med. 2012;156(8):551-9.

46. Wang YF, Chen PY, Chang W, Zhu FQ, Xu LL, Wang SL, et al. Clinical significance of tumor necrosis factor-alpha inhibitors in the treatment of sciatica: a systematic review and meta-analysis. PLoS One. 2014;9(7), e103147.

47. Karppinen J, Korhonen T, Malmivaara A, Paimela L, Kyllonen E, Lindgren KA, et al. Tumor necrosis factor-alpha monoclonal antibody, infliximab, used to manage severe sciatica. Spine (Phila Pa 1976). 2003;28(8):750-3. discussion 753-4.

48. Korhonen T, Karppinen J, Malmivaara A, Autio R, Niinimaki J, Paimela L, et al. Efficacy of infliximab for disc herniation-induced sciatica: one-year follow-up. Spine (Phila Pa 1976). 2004;29(19):2115-9.

49. Alten $R$, van den Bosch $F$. Dose optimization of infliximab in patients with rheumatoid arthritis. Int J Rheum Dis. 2014;17(1):5-18.

50. Antoniou KM, Mamoulaki M, Malagari K, Kritikos HD, Bouros D, Siafakas NM, et al. Infliximab therapy in pulmonary fibrosis associated with collagen vascular disease. Clin Exp Rheumatol. 2007;25(1):23-8.

51. Hommes DW, Erkelens W, Ponsioen C, Stokkers P, Rauws E, van der Spek M, et al. A double-blind, placebo-controlled, randomized study of infliximab in primary sclerosing cholangitis. J Clin Gastroenterol. 2008;42(5):522-6.

52. Nguyen C, Poiraudeau S, Rannou F. From Modic 1 vertebral-endplate subchondral bone signal changes detected by MRI to the concept of 'active discopathy'. Ann Rheum Dis. 2015;74(8):1488-94.

53. Fayad F, Lefèvre-Colau MM, Rannou F, Quintero N, Nys A, Macé Y, et al. Relation of inflammatory modic changes to intradiscal steroid injection outcome in chronic low back pain. Eur Spine J. 2007;16(7):925-31.

54. Nguyen C, Bénichou M, Revel M, Poiraudeau S, Rannou F. Association of accelerated switch from vertebral end-plate Modic I to Modic 0 signal changes with clinical benefit of intradiscal corticosteroid injection for chronic low back pain. Arthritis Rheum. 2011;63(9):2828-31.

55. Papuga MO, Kwok E, You Z, Rubery PT, Dougherty PE, Pryhuber G, et al. TNF is required for the induction but not the maintenance of compressioninduced BME signals in murine tail vertebrae: limitations of anti-TNF therapy for degenerative disc disease. J Orthop Res. 2011;29(9):1367-74.

56. Papuga MO, Proulx ST, Kwok E, You Z, Rubery PT, Dougherty PE, et al. Chronic axial compression of the mouse tail segment induces MRI bone marrow edema changes that correlate with increased marrow vasculature and cellularity. J Orthop Res. 2010;28(9):1220-8. 
57. Cohen SP, Hurley RW, Christo PJ, Winkley J, Mohiuddin MM, Stojanovic MP. Clinical predictors of success and failure for lumbar facet radiofrequency denervation. Clin J Pain. 2007;23(1):45-52.

58. Pincus T, Vlaeyen JW, Kendall NA, Von Korff MR, Kalauokalani DA, Reis S. Cognitive-behavioral therapy and psychosocial factors in low back pain: directions for the future. Spine (Phila Pa 1976). 2002;27(5):E133-138.

Submit your next manuscript to BioMed Central and take full advantage of:

- Convenient online submission

- Thorough peer review

- No space constraints or color figure charges

- Immediate publication on acceptance

- Inclusion in PubMed, CAS, Scopus and Google Scholar

- Research which is freely available for redistribution 